\title{
Effects of sensor, trials and knee joint variables on electrogoniometric gait recordings
}

\author{
Efeitos das variáveis sensor, coleta e articulação do joelho nos registros \\ eletrogoniométricos da marcha
}

Carnaz L', Oliveira AB', Sato TO', Hansson G-A², Coury HJCG'

\begin{abstract}
Introduction: Different sources of variations, such as electrogoniometer characteristics and procedures, may affect the accuracy and precision of movement measurements during gait. Objective: To quantify the variations and compare the effects produced by different sources of variation in electrogoniometric gait recordings: the sensors, procedures (trials) and the knee joint. Methods: Knee flexion/ extension and valgus/varus movements were recorded during gait on the treadmill. The recordings were partitioned into strides and normalized in time using a routine developed in MatLab. Mean curves for the knee during gait were derived from 50 strides, and seven conditions were evaluated: one comparing pairs of sensors; two comparing pairs of different trials (including variations due to sensors); and four comparing the right and left knees (including variations due to sensors and trials). Mean standard deviations of the differences were calculated. To estimate the variations relating to the trial and the knee joint, the compound standard deviations were transformed into variances and split into their components. Results: The variation introduced by pairs of sensors in the same model applied in one trial was smaller than the variation introduced by the same sensor used in two consecutive trials. Furthermore, the variation introduced by the difference between the right and left knees was greater than the variation introduced by the difference between sensors ( $A$ and B) and trials (1 and 2). Conclusions: It is, therefore, preferable to use different sensors in the same data recording (simultaneous) than use the same sensor in two different recordings (consecutive).
\end{abstract}

Key words: movement; measurement error; gait.

\section{Resumo}

Introdução: Diferentes fontes de variação, tais como características do eletrogoniômetro e procedimentos podem afetar a acurácia e precisão das medidas do movimento durante a marcha. Objetivo: Quantificar a variação e comparar o efeito das diferentes fontes de variação nos registros eletrogoniométricos da marcha: os sensores, os procedimentos (coletas consecutivas) e a articulação do joelho. Métodos: Movimentos de flexo-extensão e valgo-varo do joelho foram registrados durante a caminhada na esteira. Os registros foram divididos em passadas e normalizados no tempo usando uma rotina desenvolvida em MatLab. As curvas médias do joelho durante a marcha foram derivadas de 50 passadas, e sete condições foram avaliadas: uma para comparar dois sensores; duas para comparar duas diferentes coletas (incluindo a variação do sensor), e quatro para comparar os joelhos direito e esquerdo (incluindo a variação dos sensores e coletas). Os desvios-padrão médios das diferenças foram calculados. Para estimar as variações devido às coletas e à articulação do joelho, os desvios-padrão compostos foram transformados em variâncias e seus componentes isolados. Resultados: A variação introduzida por dois sensores do mesmo modelo aplicados em uma coleta foi menor do que a variação introduzida pelo mesmo sensor usado em duas coletas consecutivas. Ainda, a variação introduzida pela diferença entre os joelhos direito e esquerdo foi maior do que a variação introduzida pela diferença entre os sensores (A e B) e as coletas (1 e 2). Conclusões: Assim, é preferível usar diferentes sensores na mesma coleta de dados (simultânea) do que usar o mesmo sensor em dois registros diferentes (consecutivos).

Palavras-chave: movimento; erro de medida; marcha.

Received: 12/12/2007 - Revised: 25/06/2008 - Accepted: 10/09/2008

Department of Physical Therapy, Universidade Federal de São Carlos (UFSCar), São Carlos (SP), Brazi

${ }^{2}$ Division of Occupational and Environmental Medicine, Lund University Hospital, Lund, Sweden

Correspondence to: Helenice Jane Cote Gil Coury, Departamento de Fisioterapia da Universidade Federal de São Carlos, Rodovia Washington Luis, km 235, CP 676, CEP 13565-905, São Carlos (SP), Brazil, e-mail: helenice@power.ufscar.br 


\section{Introduction $: \therefore$.}

Physical therapists require quantitative, reliable and precise methods of evaluating impairments, disabilities and handicaps and also determining rehabilitation outcomes. Because of the feasibility of flexible electrogoniometers, they have been used to record functional movements ${ }^{1-6}$. However, different sources of variation can affect the accuracy and precision of the measurements, such as the different characteristics of particular goniometers, misalignment of the endblocks relative to the planes of movement, limited reproducibility of the application of the endblocks, vague definition that might lead to imprecise recordings of the reference position ${ }^{7-9}$ and differences between bilateral joints such as the knees during normal gait ${ }^{10,11}$.

Several studies have analyzed the different sources of variation that can affect wrist and forearm electrogoniometric recordings ${ }^{7,12}$. Nevertheless, few studies have applied flexible electrogoniometers to the evaluation of gait, and none of them evaluated the sources of variation in this application.

To estimate the variation in electrogoniometric gait recordings, particularly due to sensors, procedures and knee joints, we must consider different ways to isolate each effect. One way to determine the effect of the sensors would be to record the same knee, using different sensors, in the same trial (e.g. two similar goniometers attached to each other with double-sided adhesive tape), i.e. simultaneous measurements. To evaluate the difference between right and left knee movements, data collection could be simultaneous using different sensors, or consecutive using the same sensor. Thus, it would be possible to decide whether it is preferable to use different sensors in the same data recording (simultaneous) or the same sensor in two different recordings (consecutive), in order to achieve the smallest variation.

The objective of this study was to quantify the variations and compare the effects produced by different sources of variation in electrogoniometric gait recordings: the sensors, procedures (trials) and the knee joint.

\section{Methods : :}

\section{Subjects}

Eight healthy males (age $21.6 \pm 3.5$ years; height $170 \pm 3 \mathrm{~cm}$; weight $66.4 \pm 7.0 \mathrm{~kg}$ ) participated in the study. They did not present any musculoskeletal injuries, balance disorders or symptoms. Subjects presenting any lower-limb postural deviation were excluded in order to ensure that only subjects presenting symmetrical lower limbs were included. Furthermore, since electrogoniometer recordings are anthropometry-dependent, the subjects were selected within the height range of 165 to $175 \mathrm{~cm}$. Sixty healthy males were evaluated but only eight subjects were included because our inclusion criteria were strict and made it very difficult to find subjects. This study was developed with approval from the Ethics in Human Research Committee of Universidade Federal de São Carlos (Approval report number 035/04) and the subjects signed a consent form.

\section{Equipment}

Knee flexion/extension (F/E) and valgus/varus (V/V) movements were recorded using two biaxial flexible electrogoniometers (M110, Biometrics Ltd., Gwent, UK) and an acquisition unit (Data Logger 1001, Biometrics Ltd., Gwent, UK). The two sensors were named A and B. The sampling frequency was $1,000 \mathrm{~Hz}$.

\section{Procedures}

For two of the three trials, bilateral recordings of $\mathrm{F} / \mathrm{E}$ and $\mathrm{V} / \mathrm{V}$ were performed. One of the goniometers (A or B) was attached to the shaved lateral face of each knee with the subjects standing in anatomical position. The center of the inter-joint line was taken to be the common reference for the leg and thigh. The center of the sensor spring coincided with this line, and the endblocks were aligned over the axis of the thigh and leg, with the greater trochanter and lateral malleolus as the reference points (Figure 1). To avoid kinematic crosstalk, the aim in the alignment was to take the "true" flexion axis ${ }^{13}$. A single physical therapist was responsible for attaching the sensors. The area reserved for the sensors was marked out using a dermographic pen to allow precise reproduction of the attachments in the subsequent trials. The knee angles when standing were taken to be the reference position and the recordings of these angles were subtracted from the subsequent gait recordings. For the third trial, the goniometers were attached to one another using double-sided adhesive tape (Figure 1) then attached to the right knee.

Three gait trials were performed on each subject. The first trial was done with sensor A on the left knee (recording AL1)

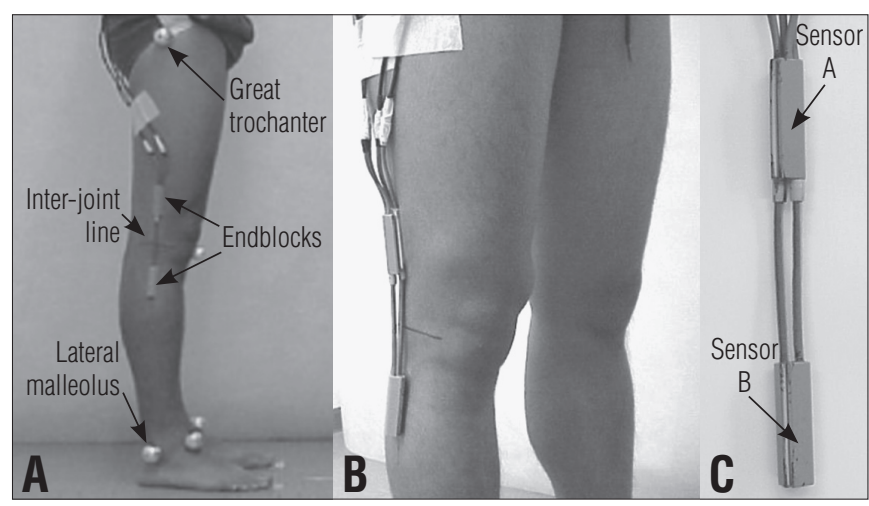

Figure 1. (A) Electrogoniometer attachment in the first and second trials; (B) and (C) Sensors A and B attached to each other, for attachment to the right knee in the third trial. 
and sensor B on the right knee (BR1); the second trial was done with sensor $A$ on the right knee (AR2) and sensor $B$ on the left knee (BL2); and the third trial was done with both sensors (A and B) on the right knee (AR3 and BR3, respectively). The sequence of the trials was randomized between the subjects and there was a five-minute interval between trials. For each trial, after recording the reference position, the subjects were gradually familiarized with a treadmill, walking at $5 \mathrm{~km} / \mathrm{h}$, and knee movements were recorded for 90 seconds.

A pilot test had been previously conducted to investigate the effects of varying the position of the goniometer. The same trained physical therapist performed palpation and attached the goniometer to the subject's knee twice. The maximum variation due to sensor replacement was $1.1^{\circ}$ for $\mathrm{F} / \mathrm{E}$ and $3.6^{\circ}$ for V/V movements. Schwartz, Trost and Wervey ${ }^{14}$ evaluated a similar effect and, although these authors did not show these results explicitly, it can be inferred from their graphs that they found errors $\leq 4^{\circ}$ for $\mathrm{F} / \mathrm{E}$ and $\leq 2^{\circ}$ for $\mathrm{V} / \mathrm{V}$ movements.

\section{Data analysis}

Data processing was performed using a routine developed in MatLab version 6.5 (MathWorks Inc., Natick, MA, USA). Through this routine, all the data were filtered using a low-pass, second-order, zero-lag Butterworth filter at $10 \mathrm{~Hz}$. The recording was partitioned into strides, which were defined as the time between two consecutive heel strikes. The heel strike was taken to be the first minimum after a maximum flexion ${ }^{15}$. The central 50 strides (corresponding to about 60 seconds of recording) for each knee were selected, and were normalized in time for both $\mathrm{F} / \mathrm{E}$ and $\mathrm{V} / \mathrm{V}$, represented by 101 data points (one for each percent of the stride). Mean F/E and V/V curves were derived from these 50 strides, and were used for the subsequent analysis.

From these data, seven differences were calculated: one comparing sensors A and B (AR3-BR3); two measurements comparing trials 1 and 2 (including the variation due to the sensor: BR1-AR2 and AL1-BL2); and four measurements comparing the right and left knees (including the variation due to the sensor: BR1-AL1 and AR2-BL2; and the variation due to the trial: AR2-AL1 and BR1-BL2).

For each comparison described above, the mean value of the difference between the two curves for the 101 points was calculated. This value was taken to be the offset and was subtracted from each of the 101 points on one curve. Hence, any systematic shift in $\mathrm{F} / \mathrm{E}$ and $\mathrm{V} / \mathrm{V}$, between the two recordings compared, was disregarded.

After offset subtraction, the mean standard deviation (SD) between the two knee curves was calculated to obtain a summary measurement of the difference, using the formula below $^{16}$.

$$
S D_{\text {mean }}=\left(\frac{\sum_{i=1}^{k} S D_{i}^{2}}{k}\right)^{\frac{1}{2}}
$$

where $\mathrm{SD}_{\text {mean }}$ is the mean of the individual point - by - point standard deviation values across all instants $(\mathrm{k}=101)$ that make up the curve, and $\mathrm{SD}_{\mathrm{i}}$ is the standard deviation value for the ith instant.

The standard deviations obtained were used to estimate the size of the different sources of variation. Since the variations due to the sensor, trial and knee joint can be regarded as independent, their contributions to the compound variations are cumulative, provided that the variations are expressed as variances. Thus, a hierarchical analysis of variance was applied; the SDs were squared, i.e. transformed into variances, and calculated for each subject and movement (F/E and V/V), separately. The variance due to the sensor was directly extracted from the condition AR3-BR3. The variance due to the trial was derived by subtracting the variance due to the sensor from the variance due to the trial plus the sensor (BR1-AR2 and AL1-BL2), and the mean value of these two estimates was used. The variance due to the knee joint was derived by subtracting the variance due to the sensor from the variance due to the knee joint plus the sensor (BR1-AL1 and AR2-BL2), and by subtracting the variance due to the trial from the variance due to the knee joint plus the trial (AR2-AL1 and BR1-BL2); and the mean value of these four estimates was used. The SDs (i.e. the square roots of the variances) were then calculated and presented in tables and figures (Figure 2 and 3). Since the data depicted in Figure 4 did not present normal distribution, the Kruskal-Wallis test was run to evaluate the differences in $\mathrm{F} / \mathrm{E}$ and $\mathrm{V} / \mathrm{V}$ relating to the sensor, trial and knee joint conditions. The post-hoc Dunn test was applied when statistical differences were identified.

\section{Results : : :}

The eight subjects and the three trials presented a mean peak amplitude of $53.3^{\circ}\left(\mathrm{SD}=1.5^{\circ}\right)$ for $\mathrm{F} / \mathrm{E}$, with a mean peak flexion of $56.2^{\circ}\left(1.6^{\circ}\right)$ and mean peak extension of $2.9^{\circ}\left(1.3^{\circ}\right)$. The $\mathrm{V} / \mathrm{V}$ movements were smaller: mean peak amplitude of $12.0^{\circ}$ $\left(1.7^{\circ}\right)$, mean peak valgus of $9.5^{\circ}\left(2.7^{\circ}\right)$ and mean peak varus of $-2.5^{\circ}\left(1.5^{\circ}\right)$. The flexion and valgus peaks were reached during the swing phase, and the extension and varus peaks occurred during the stance phase. 

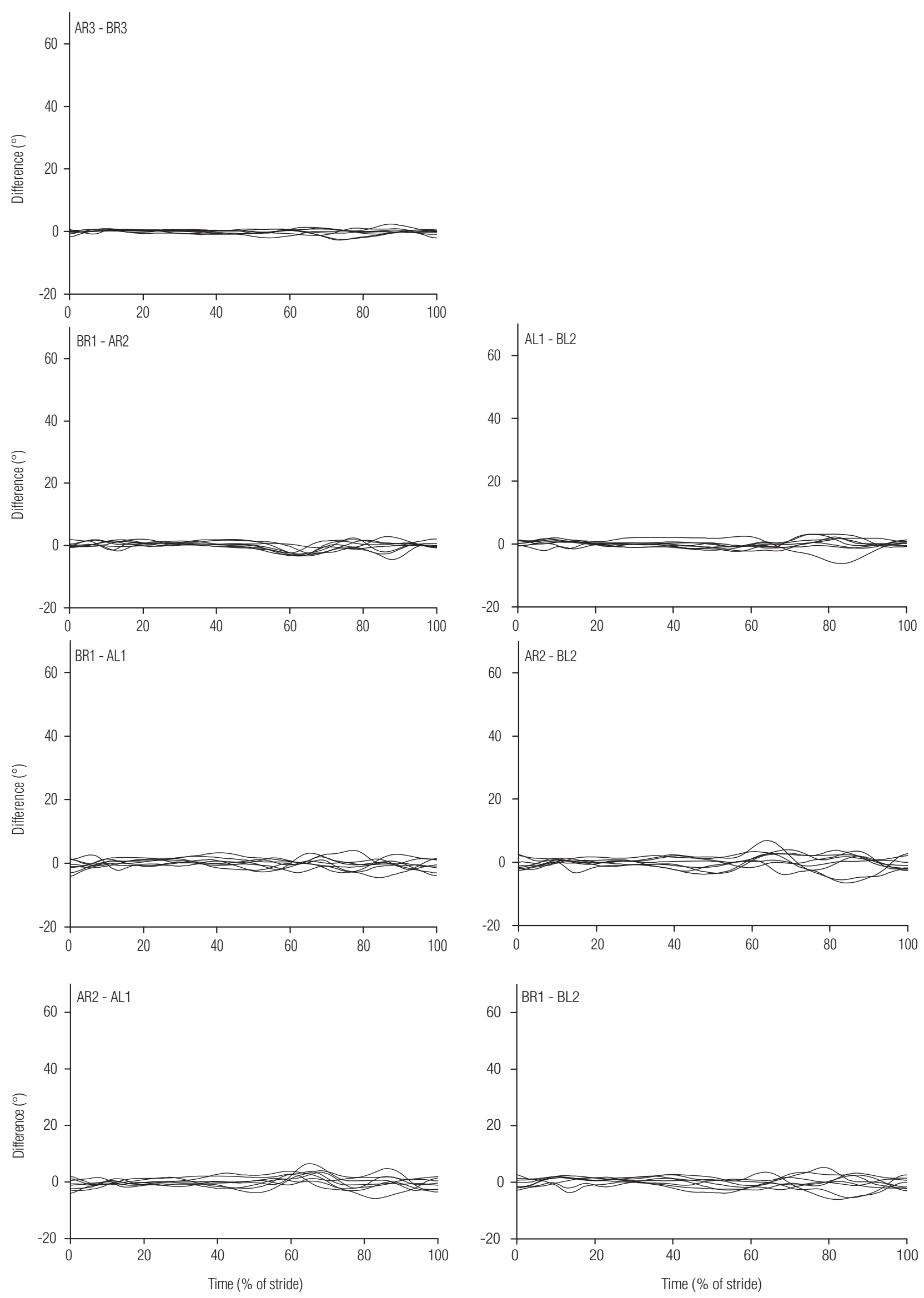

Figure 2. Difference curve graphs for all subjects in regards to each comparison of knee flexion-extension during gait. 

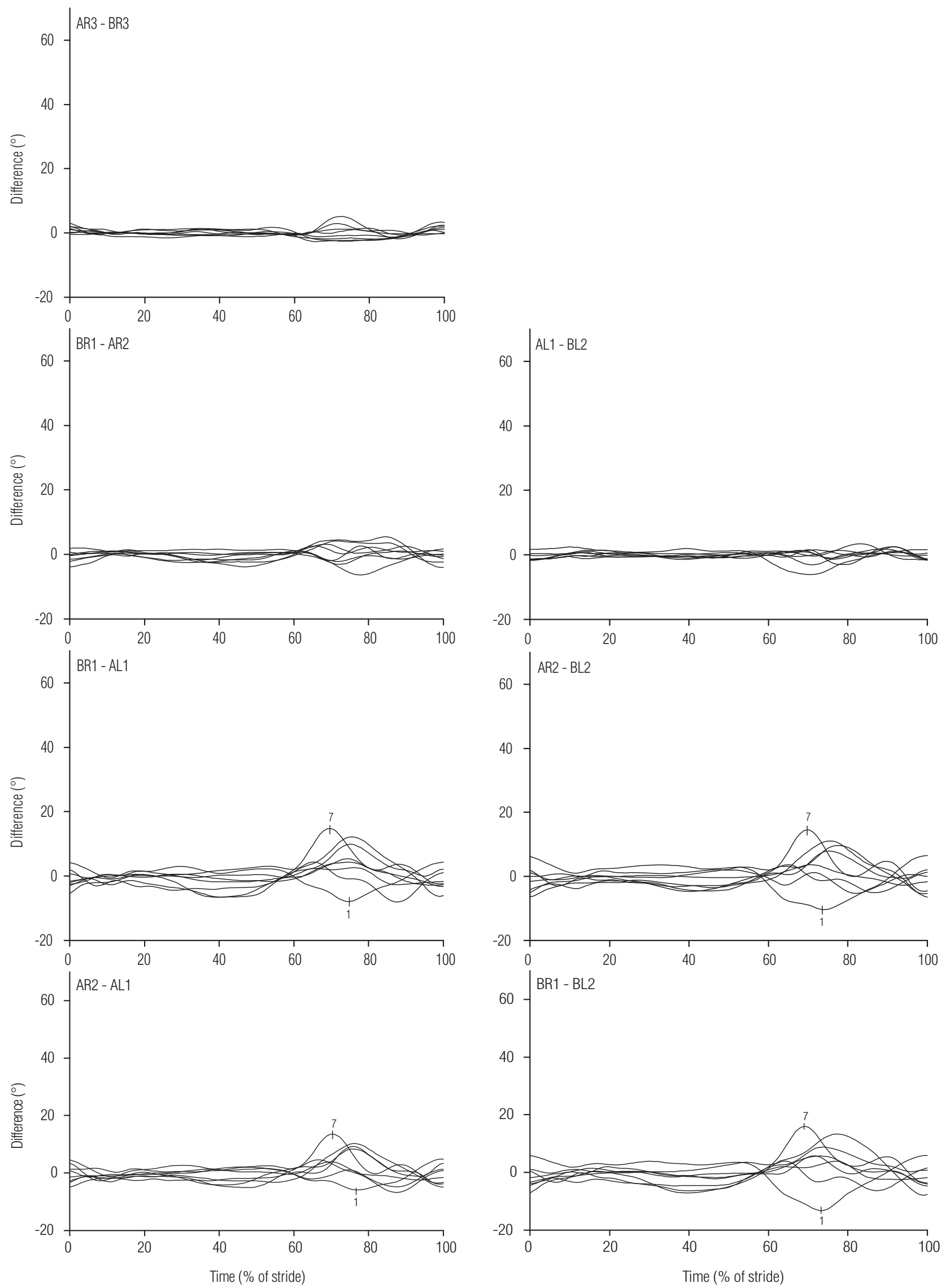

Figure 3. Difference curve graphs for all subjects, in regards to each comparison of knee valgus-varus during gait. In the knee joint comparisons (knee joint plus sensor and knee joint plus trial), it can be seen that subjects 1 and 7 presented marked differences. 
Figures 2 and 3 show the difference curves, for each subject and comparison. For all comparisons, the variation was generally higher for $\mathrm{V} / \mathrm{V}$ than for $\mathrm{F} / \mathrm{E}$. For both $\mathrm{F} / \mathrm{E}$ and $\mathrm{V} / \mathrm{V}$, and for all comparisons, the differences were more pronounced during the swing phase, i.e. 60 to $100 \%$ of stride. Sensor comparisons (AR3-BR3) for both F/E and V/V movements presented smaller deviations from zero values, and the knee curves (plus sensor and plus trial) showed larger deviations from zero, especially for V/V movements. Some subjects showed a difference between the knee joints, which, for all combinations of knee joint plus trial and knee joint plus sensor, was obvious in the graphs. For example, Figure 3 shows that, at the beginning of the swing phase (at about $70 \%$ of stride), the valgus angle for the right knee is about $15^{\circ}$ greater than for the left knee for subject 7. A difference of similar size, but in the reverse direction and somewhat later in the swing phase, can be seen for subject 1 .

All sources of variation, presented as SDs, are plotted in Figure 4. In general, the sensors represented the smallest source of variation for both $\mathrm{F} / \mathrm{E}$ and $\mathrm{V} / \mathrm{V}$. Variation due to the trial showed values with greater fluctuation than did the variation due to the sensor. For F/E, these variations were roughly at the same level, while for $\mathrm{V} / \mathrm{V}$, the variation due to the trial was smaller than the variation due to the sensor, for most of the subjects. As expected, the variation due to the trial plus the sensor was greater than the variation due to either the sensor or the trial alone, except for a few instances caused by random effects. The variations due to knee joints presented higher values, and these were generally considerably higher for $\mathrm{V} / \mathrm{V}$ than for F/E. Of course, the combined variations (knee joint plus sensor and knee joint plus trial) were greater than the knee joint variations alone. However, these differences were small, especially for $\mathrm{V} / \mathrm{V}$, i.e. the relative influence of sensor and trial on the recording of the knee joint variation was small.

Table 1 shows that, for $\mathrm{F} / \mathrm{E}$, the variation due to the sensor was smaller than the variation due to the trial (statistically non-significant), while the variation due to the knee joint was greater than the variation due to the trial, and significantly greater than the variation due to the sensor $(\mathrm{p}<0.05)$. For $\mathrm{V} / \mathrm{V}$, the variation due to the trial showed the smallest value and the variation due to the knee joint was significantly greater than the variation due to the sensor $(\mathrm{p}<0.05)$ and the trial $(\mathrm{p}<0.05)$.

\section{Discussion $: \because$.}

The knee joint variable had more influence in determining variation in the results than did the sensor and trial variables, for most of the subjects. Furthermore, the variation was much

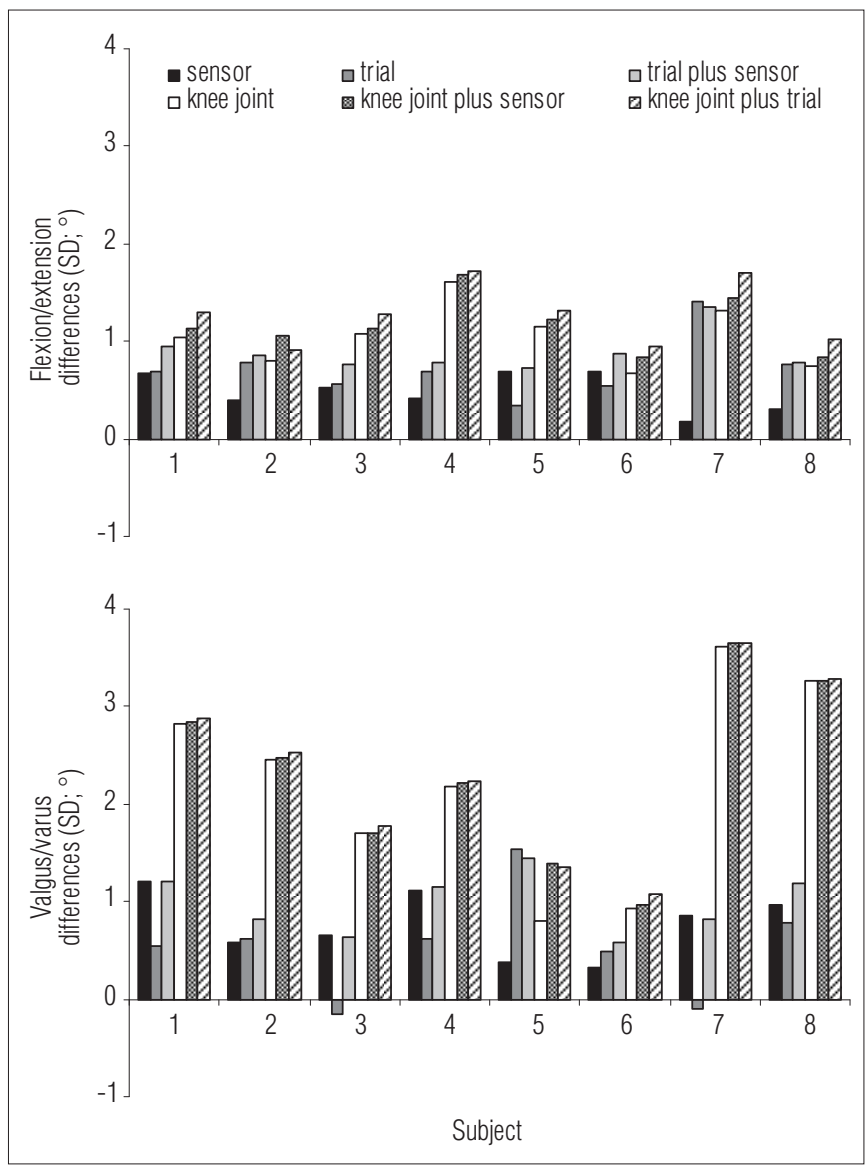

Figure 4. Compound variations (trial plus sensor, knee joint plus sensor and knee joint plus trial) and separate variations (sensor, trial and knee joint) in flexion/extension and valgus/varus for each subject (SD; ${ }^{\circ}$ ).

Table 1. Variations (standard deviation - SD; ${ }^{\circ}$ ) due to sensor, trial and knee joint. Mean values relating to eight males are shown, for both flexion/ extension and valgus/varus movements. Nonparametric analysis of variance was applied, and if the results were significant $(p<0.05)$, the Dunn test was applied to test for significant differences ${ }^{*}$ ) between sensor, trial and knee joint.

\begin{tabular}{|c|c|c|c|c|c|}
\hline & & & Sensor & Trial & Knee joint \\
\hline \multirow{3}{*}{ Flexion/extension } & Mean SD & & 0.48 & 0.72 & 1.05 \\
\hline & Dunn test & sensor & - & NS & * \\
\hline & & trial & NS & - & NS \\
\hline \multirow{3}{*}{ Valgus/varus } & Mean SD & & 0.76 & 0.54 & 2.22 \\
\hline & Dunn test & sensor & - & NS & * \\
\hline & & trial & NS & - & * \\
\hline
\end{tabular}


greater between the knee joints for $\mathrm{V} / \mathrm{V}$ than for $\mathrm{F} / \mathrm{E}$ movements. For all sources, the variation was generally greater for the swing phase than for the stance phase.

Individual sensors of the same model can produce different outcomes in a jig, where no other source of variation that would usually be present in functional situations can occur. Shiratsu and Coury ${ }^{9}$ reported up to $3^{\circ}$ difference between individual sensors (Biometrics Ltd.; XM150B) attached to a jig that reproduced full-range amplitudes for $\mathrm{F} / \mathrm{E}$ movements and deviations. In the present study, the variations (in SD) introduced by the sensors ranged from $0.48^{\circ}$ to $0.76^{\circ}$. Considering the different measurements for characterizing the differences between sensors, this is consistent with the above-mentioned study, thus indicating that this source has a small effect on knee joint measurements during gait. However, some crosstalk effect from the sensors can be expected.

Crosstalk, i.e. erroneous recordings of $\mathrm{V} / \mathrm{V}$ movements during $\mathrm{F} / \mathrm{E}$ movements, and vice versa, can occur for three reasons: (1) mechanical deviations in the geometrical properties of the goniometer sensing elements; (2) misalignment of one of the endblocks, resulting in axial rotation of the goniometer; or (3) mounting the goniometer outside of the principal plane of the movement. The first type of crosstalk is an inherent property ( fingerprint) of the particular goniometer and is of significance only for high F/E angles. This error presumably contributes towards the difference between the sensors that is observed in the $\mathrm{V} / \mathrm{V}$ movements during high flexion movements, i.e. during the swing phase. The second type of crosstalk will occur if the endblock on the shank is not aligned with the sagittal plane. In this case, pure F/E movements will cause an erroneous recording of $\mathrm{V} / \mathrm{V}$ that is proportional to the $\mathrm{F} / \mathrm{E}$ amplitude ${ }^{7}$. Prior awareness of this potential source of error was the reason for ensuring strict and careful attachment of the endblocks in the present study. However, for comparisons between the knee joints, the effect of sensor positioning cannot be disregarded. The third source of crosstalk will occur if both endblocks are misaligned in relation to the sagittal plane. If the goniometer were to be placed in the frontal plane, i.e. at the front or back of the knee (although in reality this position is practically impossible), the F/E angle would appear in the channel that would record the $\mathrm{V} / \mathrm{V}$ angle if the goniometer were to be placed in the sagittal plane. Hence, placing the goniometers in any plane that is intermediate between the sagittal and frontal planes will result in crosstalk. For example, to obtain an erroneous recording of $12^{\circ}$ of $\mathrm{V} / \mathrm{V}$ with an $\mathrm{F} / \mathrm{E}$ range of $56^{\circ}$, a misalignment of $26^{\circ}$ of one of the endblocks is required ${ }^{12}$.

Another source of variation is the occurrence of soft tissue artifacts due to the relative displacement between the electrogoniometer attachments and the anatomical reference points that are used to represent the joint angle in the static position ${ }^{8,17,18}$. Moreover, any angular differences between the endblocks will be compensated by recording a reference position (and subtracting the $\mathrm{F} / \mathrm{E}$ and $\mathrm{V} / \mathrm{V}$ angles from the subsequent recordings), as long as these angular differences do not change. One possibility for reducing the influence of local changes is to perform "spatial averaging" by applying a plate or ruler over the thigh and the shank ${ }^{8}$.

The repeatability of knee movements is clearly dependent on joint stability and adaptability ${ }^{19}$. Moreover, as the $\mathrm{V} / \mathrm{V}$ range of movement is small ${ }^{20-23}$, it can be strongly influenced by individual anatomical and functional characteristics ${ }^{24,25}$. Individual characteristics, which were analyzed here as knee joint variation, introduced the highest source of variation. However, these results must be carefully interpreted, as this knee joint variation is close to the variation due to the positioning of the goniometer (as presented in the Methods section). Other different individual characteristics are considered to have an influence on gait kinematics. Among these are age and gender ${ }^{26-30}$, which were controlled for in the present study. Furthermore, lateral dominance has been considered to have some influence on gait kinematics, although this issue still remains controversial ${ }^{27,29,30}$.

Finally, this article has provided guidelines to identify the sources of variation in electrogoniometric recordings of the knee during gait, and has suggested methodological alternatives to isolate and correct these sources of variation.

\section{Conclusions : :}

The variation introduced by two separate sensors of the same model applied in one trial was smaller than the variation introduced by recording movements in two consecutive trials using the same sensor, with regard to recording knee movements during gait. Nevertheless, the variation introduced by the difference between knee joints was greater than the variations promoted by sensors and trials, and this difference was within the variation due to sensor repositioning. Thus, it is preferable to use different sensors in the same data recording (simultaneous) than to use the same sensor in two different recordings (consecutive).

\section{Acknowledgement $: \because$.}

Fundação de Amparo à Pesquisa do Estado de São Paulo (Fapesp) process numbers: 05/59349-6; 05/53804-3; 04/15579-5; 04/07207-0. 


\section{References $: \because$.}

1. Smutz P, Serina E, Rempel D. A system for evaluating the effect of keyboard design on force, posture, comfort, and productivity. Ergonomics. 1994;37(10):1649-60.

2. Akesson I, Hansson GA, Balogh I, Moritz U, Skerfving S. Quantifying work load in neck, shoulders and wrists in female dentists. Int Arch Occup Environ Health. 1997;69(6):461-74.

3. Rowe PJ, Myles CM, Walker C, Nutton R. Knee joint kinematics in gait and other functional activities measured using flexible electrogoniometry: how much knee motion is sufficient for normal daily life? Gait Posture. 2000;12(2):143-55.

4. Hansson GA, Balogh I, Byström JU, Ohlsson K, Nordander C, Asterland $P$ et al. Questionnaire versus direct technical measurements in assessing postures and movements of the head, upper back, arms and hands. Scand J Work Environ Health. 2001;27(1):30-40.

5. Juul-Kristensen B, Hansson G-A, Fallentin N, Andersen JH, Ekdahl C. Assessment of work postures and movements using a video-based observation method and direct technical measurements. Appl Ergon. 2001;32(5):517-24

6. Arvidsson I, Hansson GA, Mathiassen SE, Skerfving S. Neck postures in air traffic controllers with and without neck/shoulder disorders. Appl Ergon. 2008;39(2):255-60.

7. Hansson GA, Balogh I, Ohlsson K, Rylander L, Skerfving S. Goniometer measurement and computer analysis of wrist angles and movements applied to occupational repetitive work. J Electromyogr Kinesiol. 1996;6:23-35.

8. Rowe PJ, Myles CM, Hillmann SJ, Hazlewood ME. Validation of flexible electrogoniometry as a measure of joint kinematics. Physiotherapy. 2001;87:479-88.

9. Shiratsu A, Coury HJ. Reliability and accuracy of different sensors of a flexible electrogoniometer. Clin Biomech. 2003;18(7):682-4.

10. Hannah RE, Morrison JB, Chapman AE. Kinematic symmetry of the lower limbs. Arch Phys Med Rehabil. 1984;65(4):155-8.

11. Maupas E, Paysant J, Datie AM, Martinet N, André JM. Functional asymmetries of the lower limbs. A comparison between clinical assessment of laterality, isokinetic evaluation and electrogoniometric monitoring of knees during walking. Gait Posture. 2002;16(3):304-12.

12. Hansson GA, Balogh I, Ohlsson K, Skerfving S. Measurements of wrist and forearm positions and movements: effect of, and compensation for, goniometer crosstalk. J Electromyogr Kinesiol. 2004;14(3):355-67.

13. Coury HJCG, Brasileiro JS, Salvini TF, Poletto PR, Carnaz L, Hansson GA. Change in knee kinematics during gait after eccentric isokinetic training for quadriceps in subjects submitted to anterior cruciate ligament reconstruction. Gait Posture. 2006;24(3):370-4.

14. Schwartz MH, Trost JP, Wervey RA. Measurement and management of errors in quantitative gait data. Gait Posture. 2004;20(2):196-203.
15. Winter DA. Kinematic and kinetic pattern in human gait: variability and compensating effects. Hum Mov Sci. 1984;3:51-76.

16. James CR. Considerations of movement variability in biomechanics research. In: Stergiou N. Innovative analysis of human movement. $1^{\text {a }}$ ed. Champaign: Human Kinetics; 2004. p. 29-62.

17. Isacson J, Gransberg L, Knutsson E. Three-dimensional electrogoniometric gait recording. J Biomech. 1986;19(8):627-35.

18. Ishii Y, Terajima K, Terashima S, Koga Y. Three-dimensional kinematics of the human knee with intracortical pin fixation. Clin Orthop Relat Res. 1997;343:144-50.

19. Heiderscheit BC. Movement variability as a clinical measure for locomotion. J Appl Biomech. 2000;16:419-27.

20. Chao EY, Laughman RK, Schneider E, Stauffer RN. Normative data of knee joint motion and ground reaction forces in adult level walking. J Biomech. 1983;16(3):219-33.

21. Li XM, Liu B, Deng B, Zhang SM. Normal six-degree-of-freedom motions of knee joint during level walking. J Biomech Eng. 1996;118(2):258-61.

22. Reinschmidt C, van den Bogert AJ, Lundberg A, Nigg BM, Murphy N Stacoff $A$ et al. Tibiofemoral and tibiocalcaneal motion during walking: external vs. skeletal markers. Gait Posture. 1997;6:98-109.

23. Benoit D, Ramsey DK, Lamontagne M, Xu L, Wretenberg P, Renström P. In vivo knee kinematics during gait reveals new rotation profiles and smaller translations. Clin Orthop Relat Res. 2007;454:81-8.

24. Ramsey DK, Wretenberg PF. Biomechanics of the knee: methodological considerations in the in vivo kinematic analysis of the tibiofemoral and patellofemoral joint. Clin Biomech. 1999;14(9):595-611.

25. Claiborne TL, Armstrong CW, Gandhi V, Pincivero DM. Relationship between hip and knee strength and knee valgus during a single leg squat. J Appl Biomech. 2006;22(1):41-50.

26. Kettelkamp DB, Johnson RJ, Smidt GL, Chao EY, Walker M. An electrogoniometric study of knee motion in normal gait. J Bone Joint Surg. 1970;52(4):775-90.

27. Gundersen LA, Valle DR, Barr AE, Danoff JV, Stanhope SJ, Snyder-Mackler L. Bilateral analysis of the knee and ankle during gait: an examination of relationship between lateral dominance and symmetry. Phys Ther. 1989;69(8):640-50.

28. Benedetti MG, Catani F, Leardini A, Pignotti E, Giannini S. Data management in gait analysis for clinical applications. Clin Biomech. 1998;13(3):204-15.

29. Maupas E, Paysant J, Martinet N, André J. Asymmetric leg activity in healthy subjects during walking, detected by electrogoniometry. Clin Biomech. 1999;14(6):403-11.

30. Sadegui $H$, Allard P, Prince F, Labelle H. Symmetry and limb dominance in able-bodied gait: a review. Gait Posture. 2000;12(1):34-45. 